\title{
FLOW IN TAKTED PROJECTS - A PRACTICAL ANALYSIS OF FLOW AND RESOURCE EFFICIENCY
}

\author{
Marco Binninger'1, Janosch Dlouhy ${ }^{2}$, and Shervin Haghsheno ${ }^{3}$
}

\begin{abstract}
In recent years, the methods of Takt Planning and Takt Control (TPTC) have gained significance in construction practice. The foundations for takted construction practices as well as the methods of Takt Planning and Takt Control have been described in numerous papers within the framework of the IGLC (Binninger u. a. 2017a; Frandson u. a. 2013; Frandson und Tommelein 2016; Haghsheno u. a. 2016; Heinonen und Seppänen 2016; Tommelein 2017). One of the primary goals of the methods is to create flow, allowing construction processes to be executed efficiently.

In order to investigate the relationship between the methods TPTC and flow in takted construction projects, the issues of how flow is implemented in takted projects during Takt Planning and Takt Control as well as how this affects project participants were discussed.

The foundations of the flow production principle were then outlined and an assessment method for determining the quality of flow was devised. The applied approach was based on the book "This is Lean" by Modig und Åhlström (2015). Hereby, workflows were measured from two perspectives and compared using an efficiency matrix.

Data from practice in the form of takt plans from 40 takted projects were analyzed and empirically assessed.

To date, an assessment of takted projects in relation to workflow has not been completed in any academic study. This paper provides a foundation for further research and sets a standard for assessment of flow in takted projects in real-life practice. This research serves as a pilot study in this field and invites further detailed studies of the characteristics of flow to be conducted in the future.
\end{abstract}

\section{KEYWORDS}

Flow, flow efficiency, takt, TPTS

\footnotetext{
Head of Lean Department, weisenbuger bau GmbH, +4915144023401, m.binninger@weisenburger.de

2 Lean Expert, BMW AG, +4915160171327, janosch.dlouhy@bmw.de

3 Professor, Karlsruhe Institute of Technology, Germany, +49-72160842646, shervin.haghsheno@kit.edu
} 


\section{INTRODUCTION}

In recent years, the methods of Takt Planning and Takt Control (TPTC) have gained significance in construction practice. One of the primary goals of these methods is to create flow, allowing construction processes to be executed efficiently. Flow is one of the basic principles of Lean Management.

Research into takted projects in relation to workflow has not been conducted in any academic study to date. This research attempts to explore the effects of flow in takted construction projects. The results can be seen as a status quo of flow in takted projects and the findings can be used to improve the effectiveness of Takt Planning in further projects.

The paper is divided into three main chapters. The section Theory of Flow outlines the theoretical foundations of flow as a production principle and shows various flow perspectives from participants of the system.

Building on this, an assessment method was created as a basis for empirical analysis of data from industry practice and described in the chapter Methodology. This chapter will answer the question of how flow can be measured and evaluated in takted projects.

Using an efficiency matrix, the assessment of 40 projects shows the quality of flow before and after execution of construction projects. In the final section, Analysis of Practical Cases, results are interpreted and their effect on the various roles in the construction process are discussed.

\section{RESEARCH QUESTION}

The aim of this paper is to identify characteristics of flow quality and its effect on takted projects. To this end, the paper aims to answer the following research question:

- How well can flow in takted production be planned and controlled?

\section{APPROACH}

The content of the paper is based on a literature review of flow and takt in construction. An evaluation system to measure the effectiveness of flow in takted projects was created. The system is based on the theory of the book "This is Lean" from Modig and Åhlström. The new developed measurement system is the base for the analysis of 40 takted projects. The results are shown in an efficiency matrix and discussed by the authors and their practical experience.

\section{THEORY OF FLOW - A LITERATURE REVIEW}

Historically, the production line and flow have played critical roles in industrial mass production. Ford recognized the potential of flow (see Womack und Jones 2003, p.22) and implemented the principle in his production line. As the Toyota Production System (TPS) is fundamentally based on mass production, flow is one of the main elements in its design. Womack und Jones (2003) also classified flow as one of the five principles of Lean Management.

The goal of the principle of flow is to arrange all the necessary activities for the creation of a product into a consistent and continuous sequence without queues, interruptions and wasted effort (see Womack und Jones 2003, p.52). The result is the development of routine and increased efficiency. For this reason flow also plays a 
critical role in the construction industry. Koskela (1992) also describes the significance of flow in his Transformation-Flow-Value (TFV) Model.

\section{FLOW PERSPECTIVES}

According to Shingo und Dillon (1989, p.4), the processes of stationary production can be considered from two perspectives. Figure 1 shows the structure of a production site. The horizontal axis shows the product perspective from raw material to a completed product ready for the customer. The second perspective describes a product from an operational perspective, in this case of a worker or of a work station (see Shingo und Dillon 1989, p.4 f).

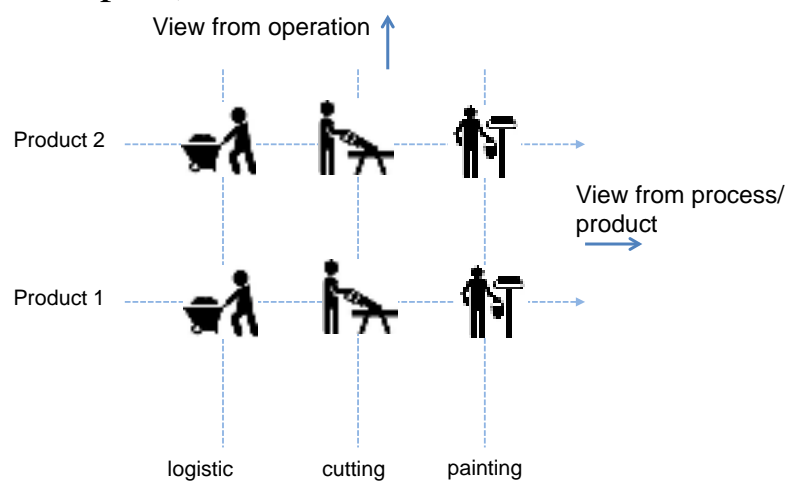

Figure 1: Structure of stationary production (in reference to Shingo und Dillon 1989, p.4)

If this structure is to be applied to construction sites, its underlying conditions and distinct features must be examined. In the construction industry, it is not the product but rather the worker who must move in flow through a construction site (see Nezval 1960, p.31). Friedrich et al. (see 2013, p.46) describe this phenomenon with the terms 'subject' and 'object'. As opposed to stationary production, the value creators (subject) in the construction industry flow through the stationary product (object). Koskela (see 2000 pp. 52-54) reinforces the theory of flow. Sacks et al. (see 2016, p.651) further develop this approach. In this paper, flow from a production perspective is defined as 'location flow', while flow from an operational perspective is defined as 'trade flow'. A perspective of a wider portfolio as per Sacks is defined with the cross-project term 'flow'. Due to the focus on individual projects in the construction sector, the portfolio flow approach was not considered in this paper.

\section{Properties Of Flow}

Nezval describes flow quality based on the three characteristics: rhythm, consistency and continuity (see 1960, p.35). Coninuity is characterized by constant fulfillment in relation to the horizontal time axis. Where flow has perfect Continuity, there are no time gaps.

Rhythm is also a time-related characteristic (see Nezval 1960, p.35). More specifically, Neval describes rhythmic work as a work that "...repeats itself after a precise time interval and takes the same amount of time each time it is repeated" (Nezval 1960, p.35).

The definition of consistency, according to Nezval, is primarily from the specific perspective of labor. In this context, it states, “... that individual workers or workforces with the same makeup will provide the same amount of work when 
repeating the same tasks with the same amount of time available. Hereby they require the same amount of raw materials and operate machinery, transport equipment etc. in a uniform way" (Nezval 1960, p.35). This suggests that the workload (production volume) of a work package is consistent across various takt times. Specifically, consistency describes the volume of production (Nezval 1960, p.35) of a work package in relation to time. Nezval does not provide a definition or precise description of this parameter.

The three characteristics can be shown as per the following diagrams (figure 2).

Diagram 1
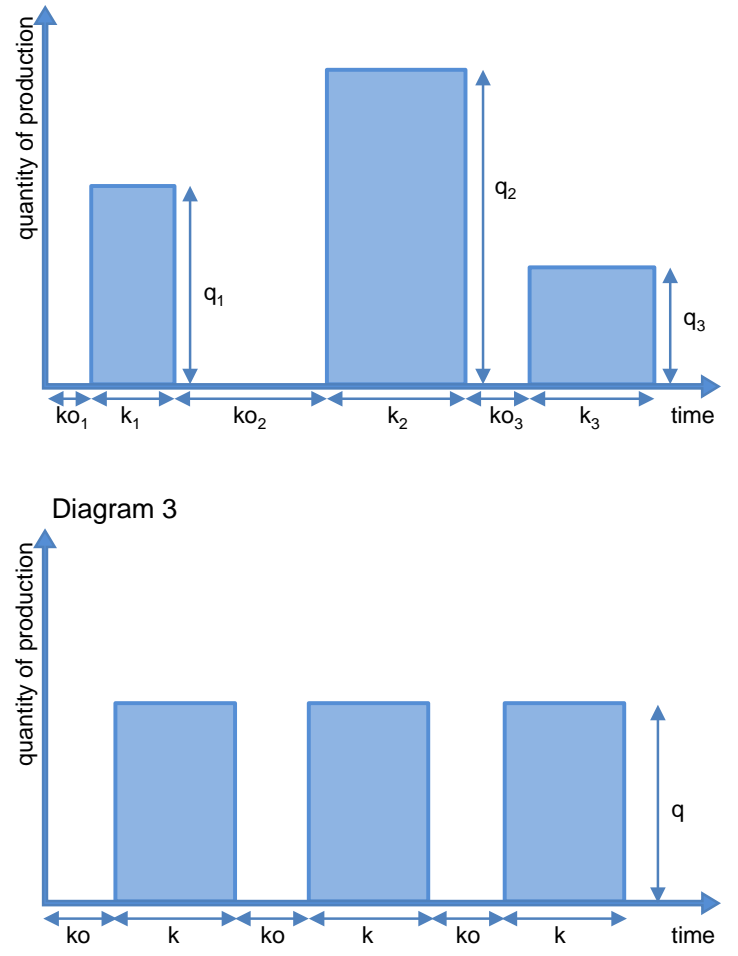

Diagram 2
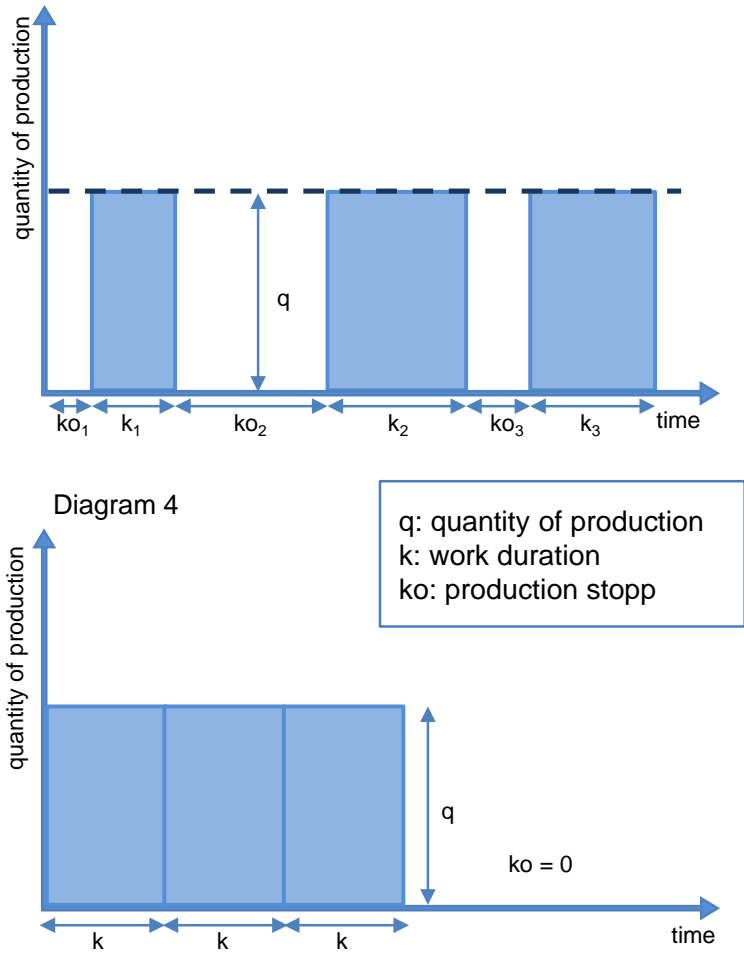

Figure 2: The characteristics of rhythm, consistency and continuity (in reference to Nezval 1960, p.36 f)

Figure 2 shows four diagrams. The $\mathrm{X}$-axes show the volume of production of the work described. The $\mathrm{Y}$-axes show time with working time expressed as ' $\mathrm{k}$ ' and interruptions expressed as 'ko'. Diagram 1 shows the baseline situation without accounting for the effects of the characteristics. The volume of production $\mathrm{q}_{\mathrm{x}}$ is variable. The durations $\mathrm{k}_{\mathrm{x}}$ and $\mathrm{ko}_{\mathrm{x}}$ are also subject to variation. Diagram 2 shows a leveled volume of production q. The division of labor can be described as consistent. Diagram 3 adds constant time intervals k and ko. The work, thereby, has both rhythm and consistency. In the case of continuous production, interruptions to working time are eliminated $(\mathrm{ko}=0)$. Therefore, diagram 4 shows consistency, rhythm and continuity (see Nezval 1960, p.35 ff).

\section{CONTINUITY AS A KEY PROPERTY}

In takted systems following the method of TPTC (Binninger et al. 2017a), the SSU approach allows consistency through dividing work into takt areas. In each takt time a uniform unit of work is carried out. Takt creates the rhythm of the system. Every unit of work starts at the beginning of a takt time and the units are defined, in the takt plan, 
to have a duration of one takt. Thereby, the characteristics of rhythm and consistency, as defined in this paper, are both covered in takted construction production and their criteria can be seen as having been met. Therefore, the characteristic of continuity was selected for assessing flow in takted projects.

\section{MODIG AND ÅHLSTRÖM's EFFICIENCY MATRIX}

In their book "This is Lean" Modig and Åhlström focus on the characteristic continuity and describe the relationship between two perspectives. They use the term 'flow' for the product perspective and the term 'resource' for the operational perspective (see Modig und Åhlström 2015, p.24). Modig und Åhlström devised an efficiency coefficient for each perspective. These can be used to compare the valuecreating time in comparison to the total time period. This matrix is shown in figure 3.

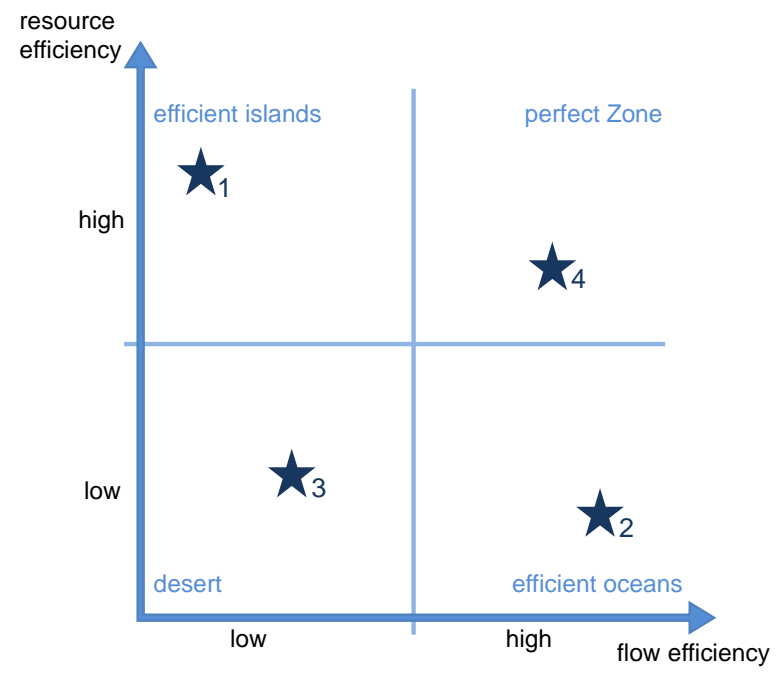

Figure 3: Flow efficiency matrix (Modig und Åhlström 2015)

In practice, the two perspectives often contradict one another. Resource efficiency is a more traditional perspective and more widely used (see Modig und Åhlström 2015 , p.7). Here, the focus lies on maximizing the utilization of machines and individual workers. This results in 'islands of efficiency' and the organization can be classified on the left side of the matrix. As a consequence, intermediate storage between different work stations and the throughput time in terms of materials increases substantially. Changes to the production sequence such as disruptions or variations in the number of orders received have a negative effect on both coefficients (see Modig und Åhlström 2015, p.119).

Modig und Åhlström's terms of 'flow efficiency' and 'resource efficiency' are not appropriate to the construction industry as it is not the product that moves, but rather the resource. In this paper flow efficiency is only discussed in general terms and is only considered from the perspectives of 'location flow' and 'trade flow'.

\section{METHODOLOGY}

The following chapter answers the questions of how flow can be integrated into takted projects and how can it be measured. 


\section{TPTC AND THE TAKTPLAN}

Flow in takted projects was investigated. The takted projects are based on the method Takt Planning and Takt Control (TPTC) as per Binninger et al. (2017a). This method is not discussed further in this paper, as only the result - the takt plan - is significant for the work under consideration.

The paper "Adjustment Mechanisms for Demand-Oriented Optimization in Takt Planning and Takt Control" (Binninger et al. 2017b) suggests that the execution of takt plans often does not go as planned due to outside influences during construction. The figure below demonstrates the impact of such influences on the takt plan.
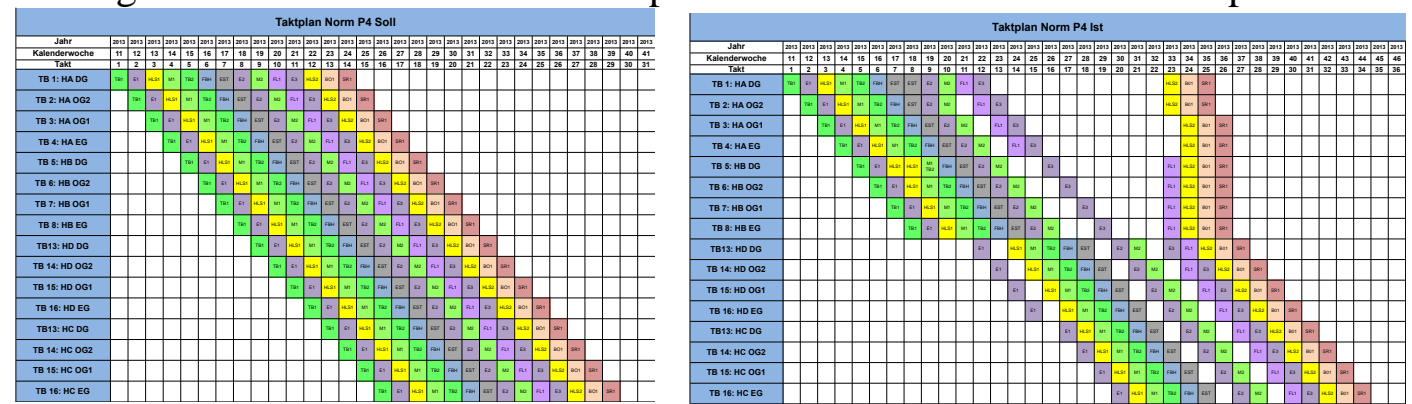

Figure 4: Comparison of planned vs. actual takt plans

\section{Flow Perspectives in the Takt Plan}

Both perspectives for considering flow can be seen in the takt plan.

The location perspective considers workflow with regards to a spatial unit (takt area) which will later be handed over to the customer. It is shown as a horizontal workflow on the takt plan. This perspective is of high interest to the customer.

The trade perspective considers the workflow in relation to a specific workforce allocated to a specific subcontractor. This is displayed in the vertical direction on the takt plan. Thereby, the work packages (boxes) are summed and shown as a cumulative curve. This perspective is of interest to the subcontractors and workers.

The general contractor considers both perspectives and seeks to harmonize them.

\section{MEASUREMENT OF CONTINUITY IN THE TAKTPLAN}

According to Modig und Åhlström (2015) flow efficiency (FE) reflects the relationship between time spent creating value and the total time taken. Applied to a takt plan the filled boxes can be considered value-creating time and the empty boxes can be considered waste in the form of unutilized time. This results in the following formula:

$$
\begin{gathered}
F E[-]=\frac{\text { filled boxes }[-]}{\text { filled boxes }[-]+\text { empty boxes }[-]} \\
\text { Formel 1: Workflow efficiency of the Takt Plan }
\end{gathered}
$$

For calculating workflow efficiency from the location perspective, the boxes of the takt plan were evaluated across the horizontal axis. For the trade perspective, the takt plan was considered along the vertical axis. In each case this results in a calculated flow efficiency from the trade perspective (FE $\mathrm{Frade}_{\mathrm{f}}$ ) and from the location persepctive ( $\left.\mathrm{FE}_{\text {Location }}\right)$. An example for calculating the efficiencies is shown in the figure below. 


\begin{tabular}{|l|c|c|c|c|c|c|c|c|c|c|c|c|c|c|c|c|c|c|}
\hline & TT 1 & TT 2 & TT 3 & TT 4 & TT 5 & TT 6 & TT 7 & TT 8 & TT 9 & TT 10 & TT 11 & TT 12 & TT 13 & TT 14 & TT 15 & TT 16 & TT 17 & TT 18 \\
\hline TA 1 & W1 & W2 & W3 & 1 & 2 & W4 & 3 & W5 & 4 & 5 & 6 & W6 & & & & & & \\
\hline TA 2 & & W1 & W2 & W3 & & & W4 & & W5 & & & W6 & & & & & \\
\hline TA 3 & & & W1 & W2 & W3 & & & & W4 & & W5 & & & W6 & & & \\
\hline TA 4 & & & & W1 & W2 & W3 & & & W4 & & & W5 & & W6 & & & & \\
\hline TA 5 & & & & W1 & W2 & W3 & & & W4 & & & W5 & & W6 & & & \\
\hline TA 6 & & & & & & & & W1 & W2 & W3 & W4 & & & W5 & W6 & & & \\
\hline TA 7 & & & & & & & & & W1 & W2 & W3 & W4 & & & W5 & & W6 \\
\hline TA 8 & & & & & & & & & W1 & W2 & W3 & & W4 & & W5 & W6 & \\
\hline
\end{tabular}

\begin{tabular}{|l|l|l|l|l|l|l|l|l|l|}
\hline 1 & 2 & 3 & 4 & 5 & 1 & 2 & 6 & 7 & 8
\end{tabular}

Figure 5: Example of different flow efficencies for a takt plan

In the example given, takt area 1 has a calculated $\mathrm{FE}_{\text {Location }}$ of 0.5 . This means that value is generated during $50 \%$ of the total time.

$F E_{\text {Location }}[-]=\frac{\text { filled boxes }[-]}{\begin{array}{c}\text { filled boxes }[-]+\text { empty boxes }[-] \\ \text { Formula } 2: \text { Location based workflow efficiency of the Takt Plan }\end{array}}=\frac{6}{6+6}=0,5=50 \%$

The trade marked in dark blue has a $\mathrm{FE}_{\text {Trade }}$ of 0.8 . This means that value is generated during $80 \%$ of the time that the subcontractor was on site.

$$
F E_{\text {Trade }}[-]=\frac{\text { filled boxes }[-]}{\text { filled boxes }[-]+\text { empty boxes }[-]}=\frac{8}{8+2}=0,8=80 \%
$$

This results in multiple flow efficiency values for trade and takt areas for each project. By calculating a median value per perspective a representative index figure can be determined for each project. This allows comparison of values for the trade and location perspectives in a matrix.

The results were assessed on the normalized level of the Three Level Model (Dlouhy u. a. 2016). Detailed consideration of the content of each box and details of works completed on site is at the micro level and therefore, is not considered in this paper.

\section{ANALYSIS OF PRACTICAL CASES}

\section{PROJECT DESCRIPTION}

In order to make an assessment of the quality of the practical application of flow in takted projects, the takt plans of 40 projects were evaluated to compare their planned and actual states. All projects were based on a takt time of one week. The projects can be categorized as turnkey construction, encompassing a range from interior fit-outs to apartment buildings and from aged care facilities to offices.

\section{RESULTS}

The average flow efficiency of the 40 selected projects are shown in an efficiency matrix based on Modig and Åhlström (2015). The flow efficiency from the location perspective is shown on the $\mathrm{X}$-Axis while flow efficiency from the trade perspective is shown on the Y-Axis. Each project is shown as a data point on the matrix. The result is plotted in figure 6 . Red data points show the results as projected by the takt 
plans while the blue data points show the actual status at the end of each project. The darker colored point in each color reflects the average values.

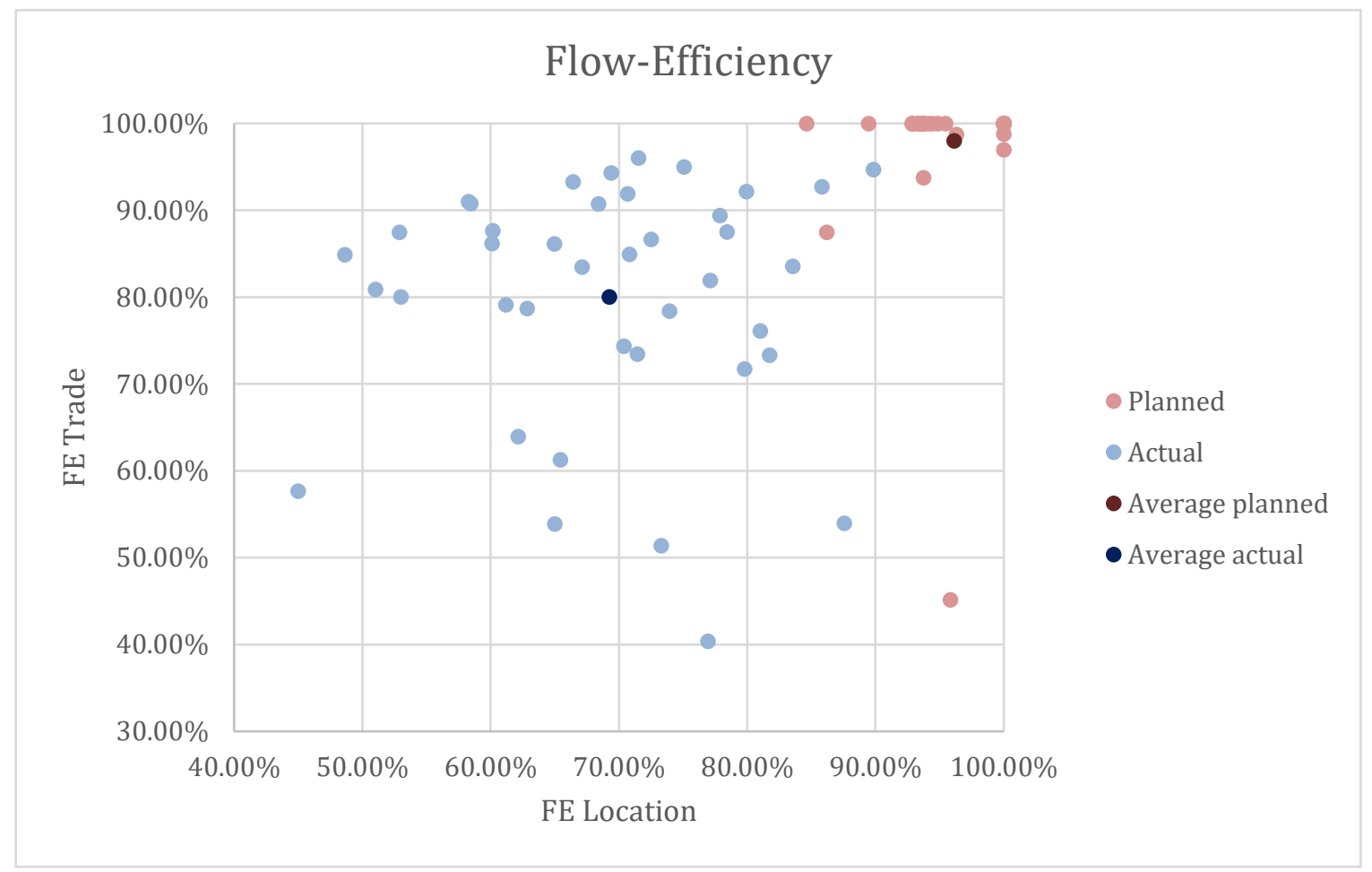

Figure 6: Flow Efficiency matrix

The takt plans in their planned state show only isolated instances of empty boxes. This is reflected in their high flow efficiency ratings. The takt plans intend for average flow efficiencies of $98.02 \%$ from the trade perspective and $96.13 \%$ from the location perspective. The location perspective lies slightly below the trade perspective because these are also influenced by drying times. It is likely that the takt plans, derived from the process of Takt Planning, represent the ideal outcome for which projects should aim.

During the construction phase, various situations affecting the takt plan arise. As a consequence, the quantity of gaps within the takt plan increases significantly, resulting in a more scattered appearance. This becomes clear in the efficiency matrix where the blue data points lie significantly below the red data points. The average flow efficiency in the actual situation is $69.25 \%$ as considered from the location perspective and $80.03 \%$ from the trades perspective. The average values are shown in the following table. The results don't depend on the project type.

Table 1: Overview of average flow efficiency

\begin{tabular}{lccc} 
& $\begin{array}{c}\text { Planned } \\
{[\%]}\end{array}$ & $\begin{array}{c}\text { Actual } \\
{[\%]}\end{array}$ & $\begin{array}{c}\text { Difference } \\
{[\% \text { points }]}\end{array}$ \\
\hline FE Trade & 98,02 & 80,03 & $-17,99$ \\
FE Location & 96,13 & 69,25 & $-26,88$ \\
\hline
\end{tabular}




\section{CONCLUSION AND OUTLOOK}

The paper is a first step in the field of flow in takted projects. In this research paper the basis on measurement of flow is given. 40 projetcs were analyzed and the results were discussed. The results can be used for further projects.

The paper shows that the relationship between flow and takt are decisive in determining the success of on-site execution of construction projects. Various perspectives of flow must be considered and harmonized.

The first finding of the paper is the decrease of flow efficiency during Takt Control. There is a significant difference between planned flow efficiency and the actual situation as assessed after project completion. The difference between the two is not due to coincidence, but rather it is the result of takt control, which reacts with various actions as a result of real-life factors on construction sites. The actions are referred to as mechanisms and are described in the paper 'Adjustment Mechanisms for Demand-Oriented Optimization in Takt Planning and Takt Control' (Binninger et al. 2017b). The individual mechanisms have various consequences with regard to the workflows of the takt plan, although they are not the focus of this paper. In practice, it is particularly important to recognize relationships between various factors and to select the appropriate mechanism in response. As general contractors must consider and address both perspectives appropriately, because it's a mix of short delivery times of the product from the client perspective and stability and consistency of resources from the subcontractors perspective. This represents an area of great research potential. Further research is neccessary in order to understand the question why the flow efficiency decreases during construction control.

Moreover, the differences in flow efficiency between the location and trade perspectives are notable. From the trade perspective a higher level of flow efficiency is measured. This suggests that management of construction sites is primarily focused on the trades perspective, giving preference to the perspectives of subcontractors and workers. A reason for this could be the current market situation, where there is an existing lack of resources in the construction sector. If for example the trade perspective would not be focused, the cost can overrun the budget, because of an unstable use of resources. These findings underline those of Modig und Ählström and seem plausible when considering the current market situation in the construction industry. The construction manager decides on the mechanisms to be implemented and discusses these with subcontractors. Provided the mechanisms do not have any effect on the duration of construction as per the contract, the change has no effect on the product or customer. The trade however, is affected by the change.

Overall the two perspectives belong together and a focus on just one perspective is not useful. Further research is necessary to understand the relationship between the perspectives and the interaction and influence between them. Depending on the type of construction site, differing perspectives may have priority. E.g. construction projects with high focus on construction time would likely concentrate on the location flow. It is another field for further research.

\section{REFERENCES}

Binninger, Marco; Dlouhy, Janosch; Haghsheno, Shervin (2017a), „Technical Takt Planning and Takt Control in Construction.“. In: 25th Annual Conference of the International Group for Lean Construction. Heraklion, Greece, S. 605-612. 
Binninger, Marco; Dlouhy, Janosch; Steuer, Dominik; u. a. (2017b), „Adjustment Mechanisms for Demandoriented Optimisation in Takt Planning and Takt Control“. In: 25th Annual Conference of the International Group for Lean Construction. Kreta, Griechenland, S. 613-620.

Dlouhy, Janosch; Binninger, Marco; Oprach, Svenja; u. a. (2016), „Three-Level Method of Takt Planning and Takt Control - a New Approach for Designing Production Systems in Construction". In: Proceedings of the 24th Annual Conference of the International Group for Lean Construction. Boston, USA.

Frandson, Adam; Berghede, Klas; Tommelein, Iris D. (2013), „Takt Time Planning for Construction of Exterior Cladding“. In: 21th Annual Conference of the International Group for Lean Construction. Fortaleza, Brazil, S. 527-536.

Frandson, Adam G.; Tommelein, Iris D. (2016), „,Takt Time Planning of Interiors on a Pre-Cast Hospital Project". In.:

Friedrich, Till; Meijnen, Peter; Schriewersmann, Florian (2013), „Lean Construction die Übertragung der Erfolgsmodelle aus der Automobilindustrie" ("Lean Construction - Transfer of the sucessfactors from the automotive industry"). In: Motzko, Christoph (Hrsg.) Praxis des Bauprozessmanagements ("Construction Management in Practise"). Weinheim, Germany: Wiley-VCH Verlag GmbH \& Co. KGaA, S. 37-52, DOI: 10.1002/9783433602973.ch2. — ISBN: 978-3-43360297-3

Haghsheno, Shervin; Binninger, Marco; Dlouhy, Janosch; u. a. (2016), „History and Theoretical Foundations of Takt Planning and Takt Control“. In: 24th Annual Conference of the International Group for Lean Construction. Boston, USA.

Heinonen, Aleksi; Seppänen, Olli (2016), „Takt Time Planning: Lessons for Construction Industry from a Cruise Ship Cabin Refurbishment Case Study“. In.:

Koskela, Lauri (2000), „An Exploration Towards a Production Theory and Its Application to Construction“. Espoo: Technical Research Centre of Finland.

Koskela, Lauri (1992), Application of the New Production Philosophy to Construction. Stanford University.

Modig, Niklas; Åhlström, Pär (2015), This is Lean: Resolving the Efficiency Paradox. Stockholm: Rheologica Publishing. — ISBN: 978-91-87791-09-3

Nezval, Jiri (1960), Grundlagen der Fließfertigung in der Bauproduktion. ("Basics of flow production in construction") 1. Auflage. Verlag für Bauwesen Berlin.

Sacks, Rafael (2016), „What constitutes good production flow in construction?“. In: Construction Management and Economics. 34 (9), S. 641-656, DOI: 10.1080/01446193.2016.1200733.

Shingo, Shigeo; Dillon, Andrew P. (1989), A Study of the Toyota Production System: From an Industrial Engineering Viewpoint. CRC Press. - ISBN: 978-0-91529917-1

Tommelein, Iris D. (2017), „Collaborative Takt Time Planning of Non-Repetitive Work". In: Proceedings ot the 25th Annual Conference of the International Group for Lean Construction., S. 745-752.

Womack, James P.; Jones, Daniel T. (2003), Lean Thinking: Banish Waste and Create Wealth in Your Corporation. 1st Free Press ed., and updated. New York: Free Press. — ISBN: 978-0-7432-4927-0 